\title{
DIAGNOSIS OF PULMONARY MIDDLE LOBE DISEASE IN CHILDREN
}

\author{
BY
}

\author{
A. MORTON GILL, M.D.(Lond.), M.R.C.P.(Lond.), \\ AND
}

J. E. G. PEARSON, B.M., B.Ch.(Oxon.).

(From the Children's Department, Middlesex Hospital, London.)

In adults affections of the middle lobe of the lung although uncommon, are now well recognized. In children middle lobe disease is not only far more rarely seen but, owing to the fact that few or no clinical signs may be produced, diagnosis is rendered considerably more difficult. Indeed, as it is hoped to show in this communication, a correct diagnosis, and therefore efficient treatment, depends upon first, symptoms pointing to pulmonary disease and second, and as an immediate result of these, good $x$-ray pictures of the chest including lateral views. Particular stress must be placed on the latter and it must be emphasized that an ill child presents no insuperable difficulty, since both antero-posterior and lateral views, showing sufficient detail for an accurate diagnosis, can be obtained with a portable machine. Many of the skiagrams here published were taken in this way.

Radiological and applied anatomy.

The interpretation of x-rays taken to show the middle lobe, and particularly the interpretation of lateral views, depends upon an accurate knowledge of the radiological anatomy of that lobe and of the fissures which bound it. This perhaps can best be illustrated by means of diagrams and fig. 1 represents an antero-posterior view of the right lung with its fissures. Fig. 2 shows a strictly lateral view of the right lung and it is evident that in this view the middle lobe is approximately triangular in shape and that the base of the triangle rests upon both diaphragm and sternum. It will be shown that this relationship is unaltered when the middle lobe alone is affected by disease, so that diagnosis is possible merely from a consideration of the position of the base of the said triangle (see fig. 6 and 7). This is an important diagnostic point which does not seem to have been previously emphasized. In sharp contrast is the appearance seen in effusions occupying the interlobar fissures. Fig. 3 represents a lateral view of an effusion in the lower part of the large fissure. It will be seen that the base of the shadow rests entirely upon the diaphragm (see fig. 14). An effusion in the small fissure, however, produces a shadow with its base resting solely on the sternum. This appearance is represented in fig. 4 and a good example has been published by St. Engel and Schall ${ }^{1}$. It must be realized that these figures are purely schematic since, as Sante $^{2}$ points out, the margins of an 
interlobar effusion may be convex if the fluid is under sufficient tension to exert pressure upon the adjacent lung tissue. This, however, does not affect the importance of the position of the base of the shadow in the differential diagnosis between affections of the middle lobe and interlobar effusions.

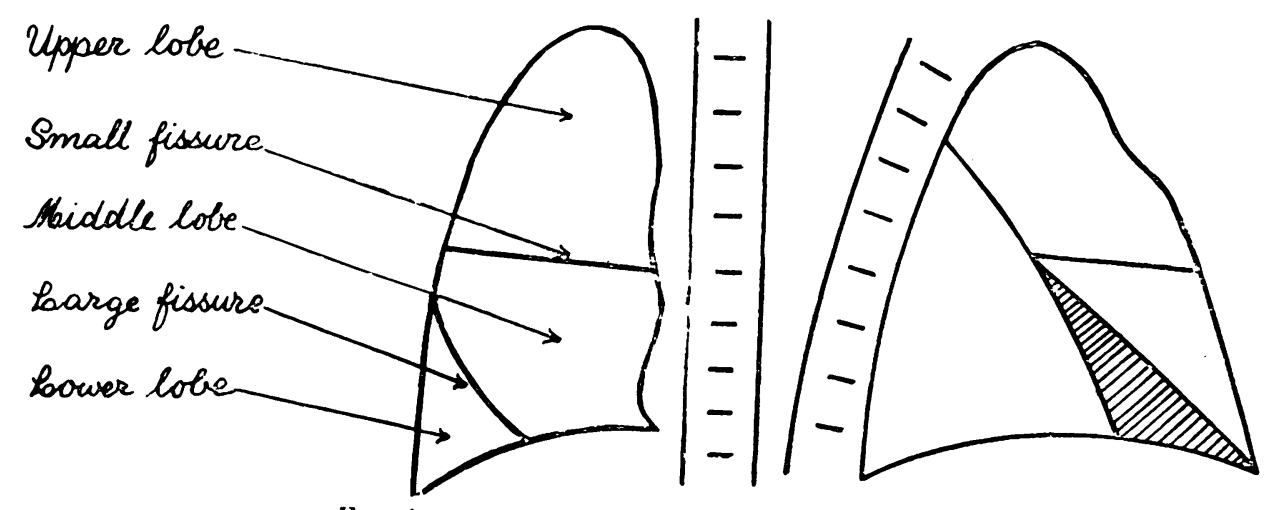

Firi. 1.

Fiti. 3

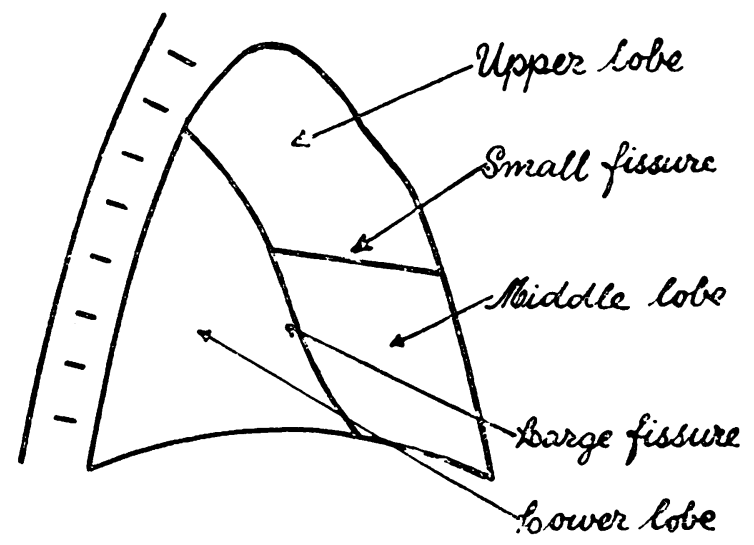

Fis. 2.

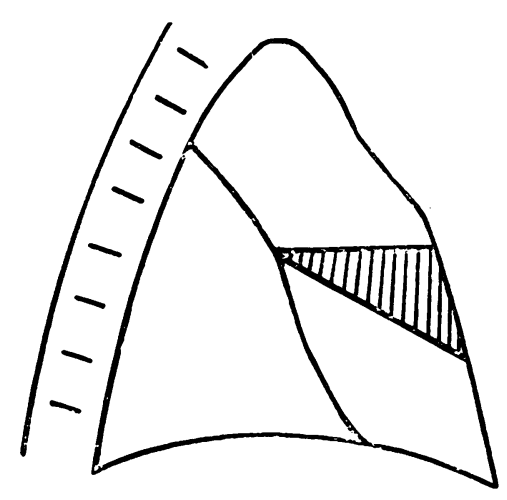

Fig. 4.

Diseases of the middle lobe.

The middle lobe of the lung is naturaliy subject to those diseases which affect the other lobes. These include, in children, pneumonia, collapse, bronchiectasis, epituberculosis and abscess. This communication is only concerned with those conditions affecting the middle lobe, which will produce a triangular shadow in the right mid-zone, and with their differential diagnosis. An abscess of the middle lobe does not produce a triangular shadow of this nature, and the authors have been unable to find any record of epituberculosis confined to the middle lobe or giving rise to this appearance. It is proposed to describe typical examples of the remaining three conditions.

\section{Clinical records-(a) Middle lobe pneumonia.}

Case 1. T. M.; a boy aged five years, had previously suffered from measles, German measles and rickets. On the day of admission (26.12.35) his mother noticed that he was listless and feverish, 
and he vomited once. His breathing became difficult and he complained of upper abdominal pain. On examination he was flushed: the respirations varied between 36 and 44 per minute and were grunting in character. The temperature was $103^{\circ} \mathrm{F}$. and pulse rate 120. In the lower part of the axilla on the right

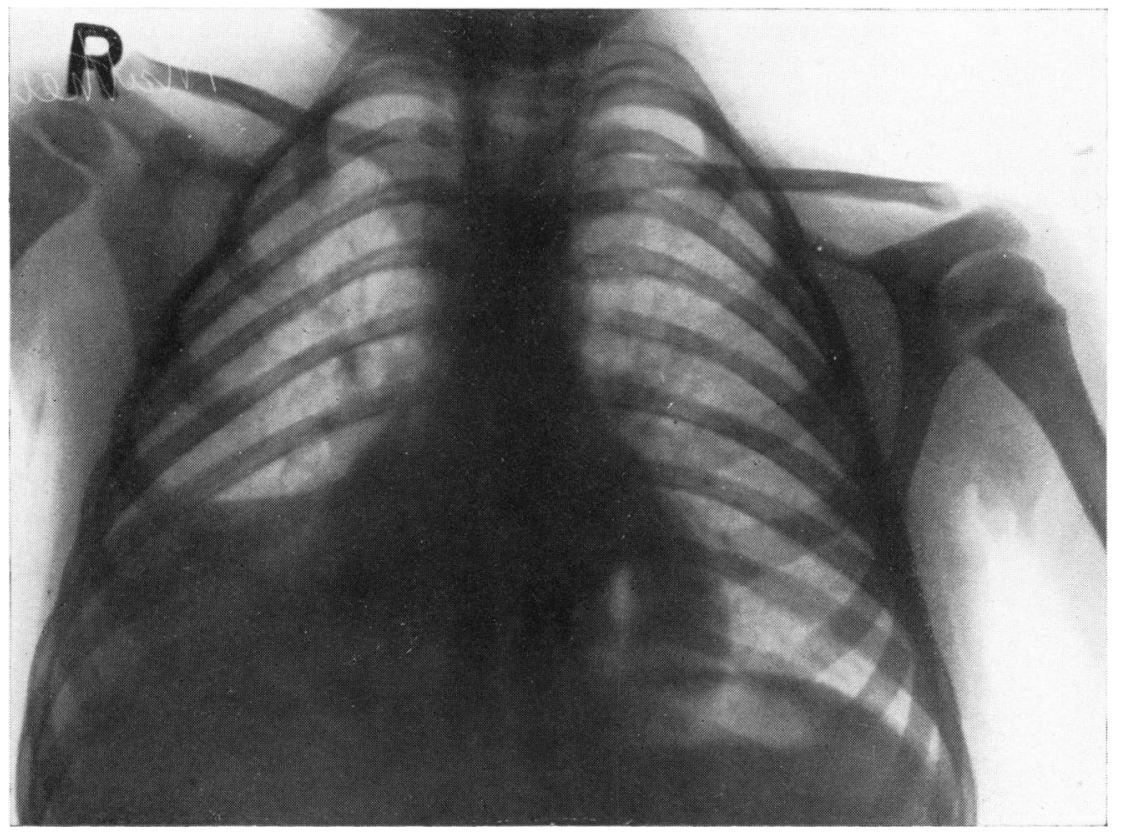

FIG. 5.

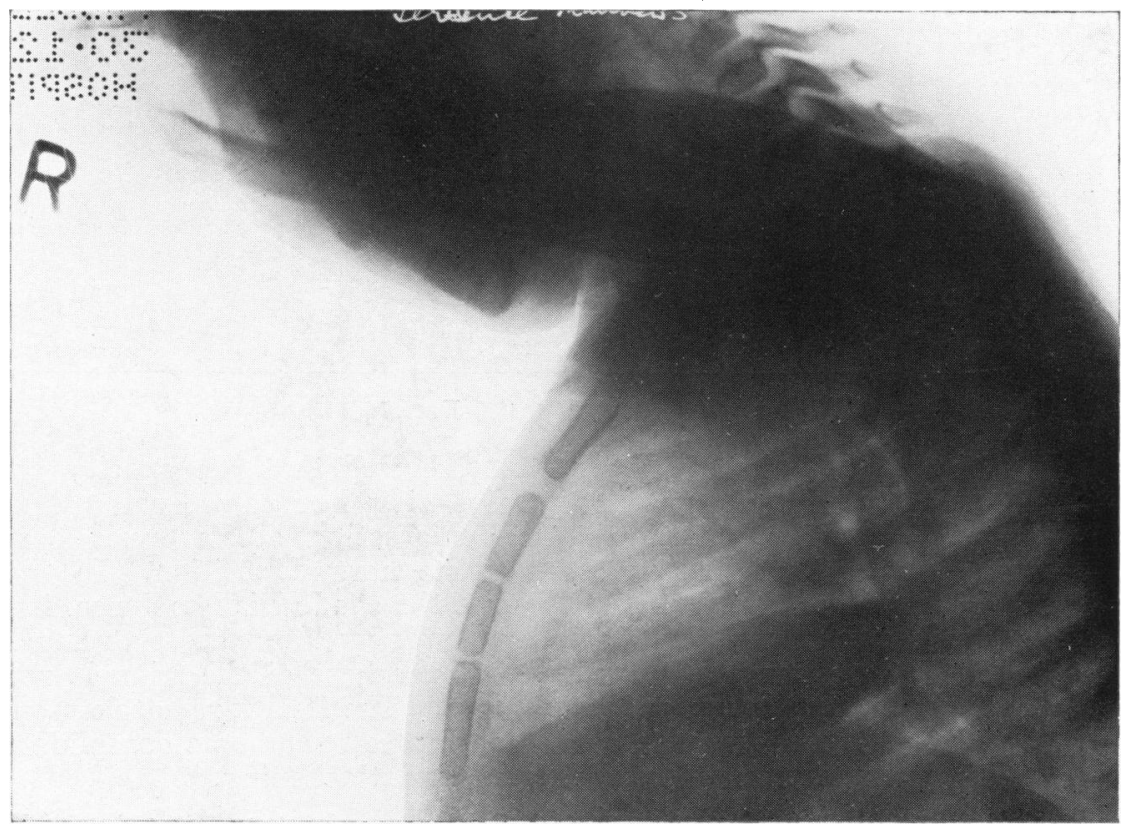

Fig. 6. 
side there were fine râles and weak breath sounds and within forty-eight hours the classical signs of consolidation had developed. X-ray examination (30.12.35) shows in the anteroposterior view (fig. 5) a homogeneous opacity at the right base with a sharply defined upper margin, while the lower margin is less dense and is ill-defined. There is some enlargement of the hilar glands and slight displacement of the heart to the right. In the lateral view (fig. 6) there is a triangular opacity, with its apex directed towards the hilum, the base of the triangle being situated partly on the lower end of the sternum and partly on the diaphragm. The temperature remained sustained, the respiration rate varying between 40 and 64 per minute, until the fourth day, when a pseudo-crisis occurred. The true crisis was seen on the seventh day, following which the child made an uninterrupted recovery.

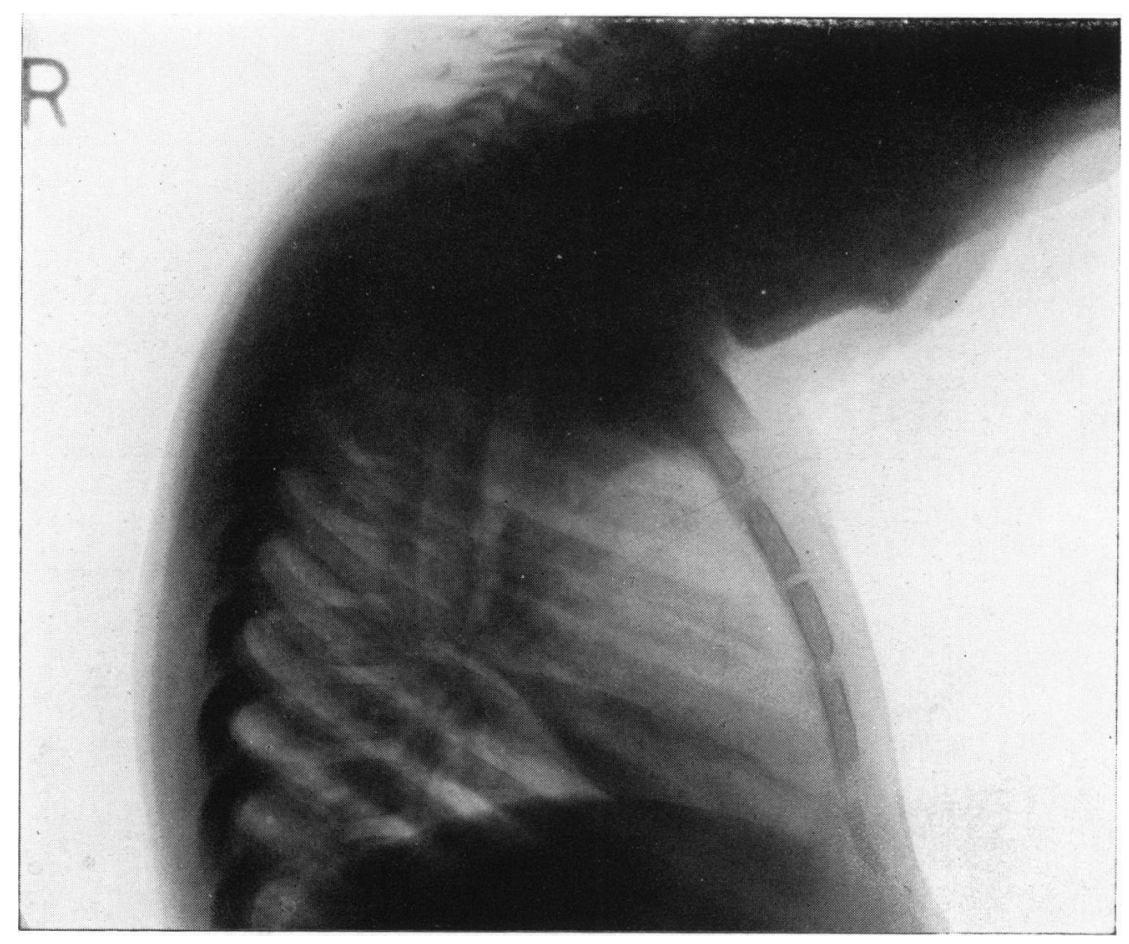

Fig. 7.

Further x-ray (7.1.36) showed that the opacity previously seen in the antero-posterior view had considerably cleared, no longer presenting sharp demarcation of its upper border and the heart has returned to its normal position. In the lateral view, however, (fig. 7) while the shadow is less dense, its borders are, if anything, more clearly defined and serve to demonstrate, in a beautiful manner, that the base of the triangle rests upon both sternum and diaphragm. The final x-rays taken on 13.1.36 showed complete resolution of the pneumonic consolidation with some residual interlobar pleural thickening.

Commentary.-Pfaundler and Schlossman ${ }^{3}$ state that in middle lobe pneumonia an antero-posterior view is sufficient for diagnosis, but St. Engel and Schall ${ }^{4}$ and Stoloff ${ }^{5}$ consider that lateral $\mathrm{x}$-ray examination is essential 
and with this the authors are in emphatic agreement. Reichle and York ${ }^{6}$ make a similar plea for the use of lateral views in the diagnosis of interlobar effusions.

\section{(b) Middle lobe collapse.}

Caise 2. C. M., a boy aged eight years, whose previous history included measles and pneumonia at two, pertussis and bronchopneumonia at six and bronchopneumonia again at seven, had in March, 1934, at the age of seven, a further attack of pnemonia involving the right upper lobe. Following this he attended outpatients, but his cough persisted and led to an x-ray examination of his chest (7.5.34). This (fig. 8) shows in the antero-posterior view, a triangular opacity in the right mid-zone, with a sharply defined upper margin and an ill-defined lower one (c.f. fig. 5). Unfortunately, a strictly lateral x-ray picture was not obtained

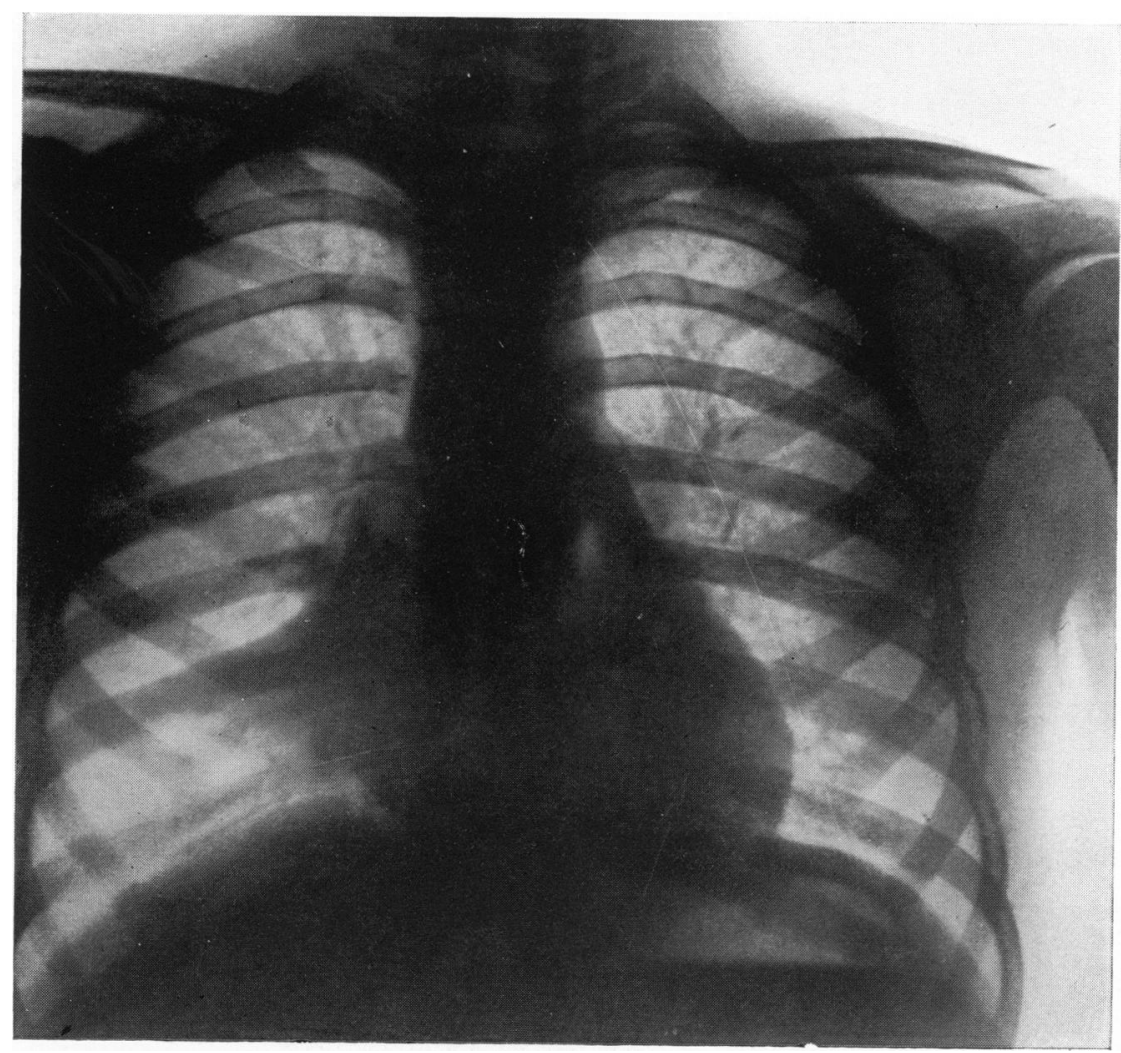

Fig. 8.

and the right anterior oblique view which was taken made it impossible to differentiate between middle lobe disease and an effusion in the small fissure. In actual fact, the latter was the radiological diagnosis made at that time, but a subsequent x-ray after lipiodol led to the suspicion of collapse of the middle lobe and bronchoscopy was therefore performed, when a plug of mucus was removed from the occluded bronchus. Ten days later a skiagram (fig. 9) shows complete re-expansion of the affected lobe. 
(c) Middle lobe bronchiectasis.

As far as can be ascertained, bronchiectasis confined to the middle lobe has not been described in a child, although it might theoretically follow atelectasis due to obstruction of the bronchus. The following case is included, despite the fact that the bronchiectatic process is not limited to the middle lobe, because the antero-posterior x-ray (fig. 10) presented a triangular shadow in the right lung similar to that seen in the above two cases.

Case 3. A. S., a girl aged nine years, had pertussis at the age of five. This was followed by cough and sputum, the latter gradually increasing in quantity and at the present time amounting to $8 \mathrm{oz}$.

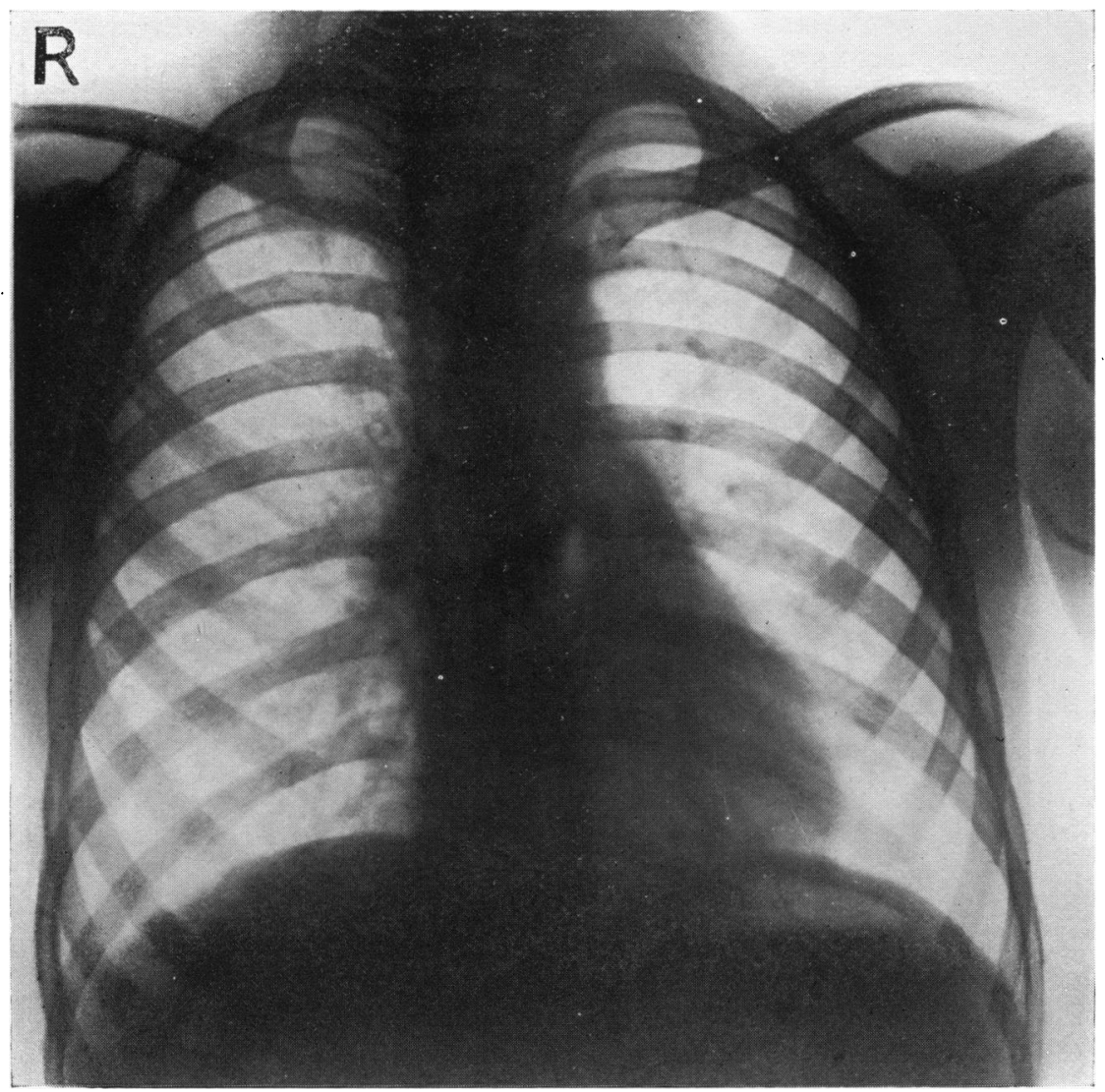

Fig. 9.

in twenty-four hours, purulent and of a foul odour. On examination there was clubbing of the fingers, at both bases the percussion note was impaired, the breath sounds were weak and accompanied by medium bubbling râles. X-ray examination (10.2.36) is pathognomonic of bilateral basal bronchial dilatation (fig. 10), but in addition, there is a triangular shadow on the right side, with a sharply-defined upper border, directed outwards from the hilum. The lower border is ill-defined (c.f. fig. 5 and 8). In the lateral view there is no sharp demarcation of this shadow. On 27.2.36 lipiodol was introduced in order to outline the right 
bronchial tree. This confirms the presence of bronchiectasis (fig. 11), showing that both middle and lower lobes are diseased. The triangular shadow seen in fig. 10 is due to partial collapse of that part of the lower lobe supplied by the anterior branch of the lower lobe bronchus.

\section{Differential diagnosis.}

The conditions, other than those already described, which will produce a triangular shadow in the right mid-zone, include pneumonia affecting the lower part of the upper lobe or the upper part of the lower lobe and interlobar effusions, either in the large or in the small fissure. Pneumonia affecting part of a lobe, while it may produce, in the antero-posterior view, an appearance simulating middle-lobe disease, is at once differentiated by means of a strictly lateral examination, as will be realized from a

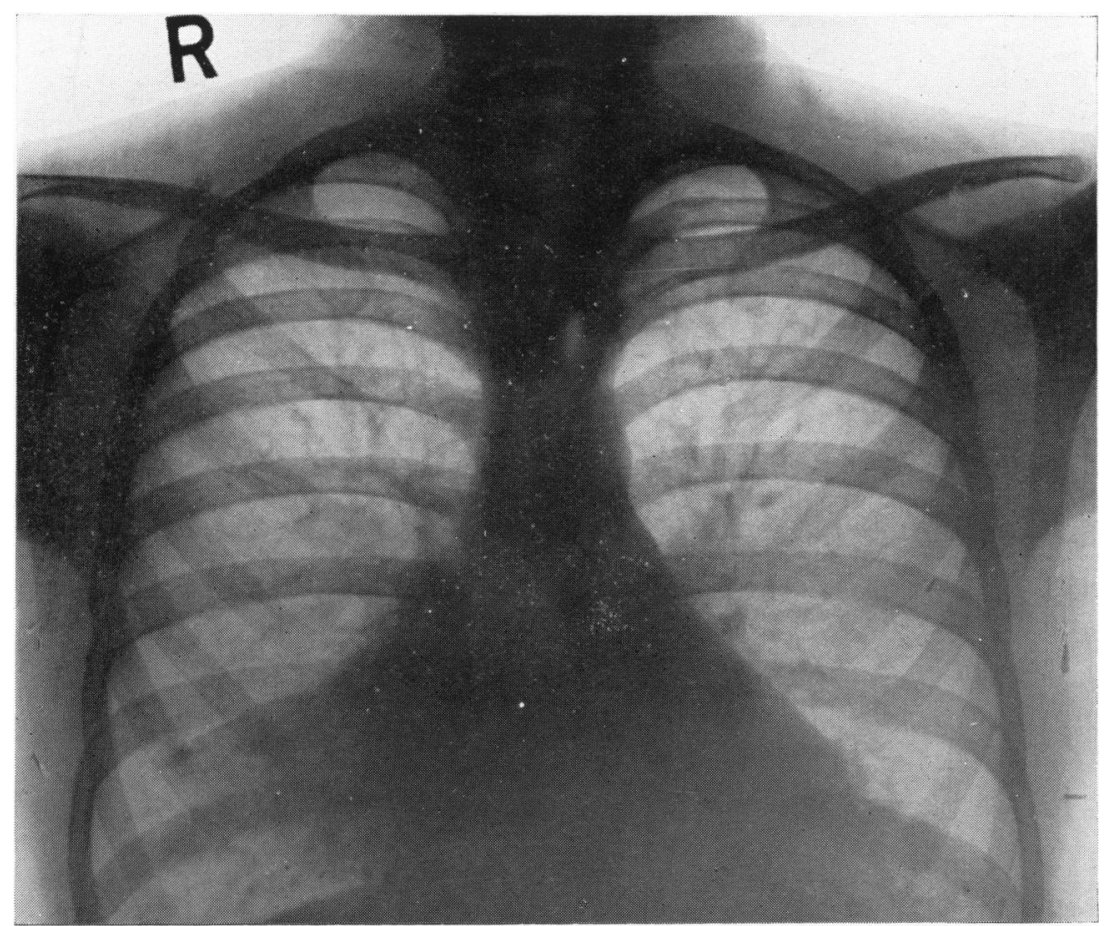

Fig. 10.

consideration of the radiological anatomy of the part. On the other hand, as a result of inaccurate radiological interpretation, interlobar effusions have often in the past been mistaken for middle lobe affections and vice-versa. It is suggested that such errors may be obviated if the radiological points emphasized in the earlier part of this paper are borne in mind. The following case illustrates some of the difficulties associated with a mediastino-interlobar effusion into the large fissure.

Case 4. B. M., a girl aged five, whose previous illnesses included measles and bronchopneumonia, was admitted in 1933, to hospital on account of loss of weight. X-ray examination showed enlarged mediastinal glands, and the Mantoux 
tuberculin reaction $(1: 1,000)$ was strongly positive. On discharge she was sent to convalescent home and on her return attended the Middlesex Hospital Welfare Clinic. On 27.12.35, at the age of five, her mother said that the child was not eating, had a cough and complained of abdominal pain. It was found that she had lost over $2 \mathrm{lb}$. in weight since her last attendance three weeks previously. On examination she was pale and languid, but

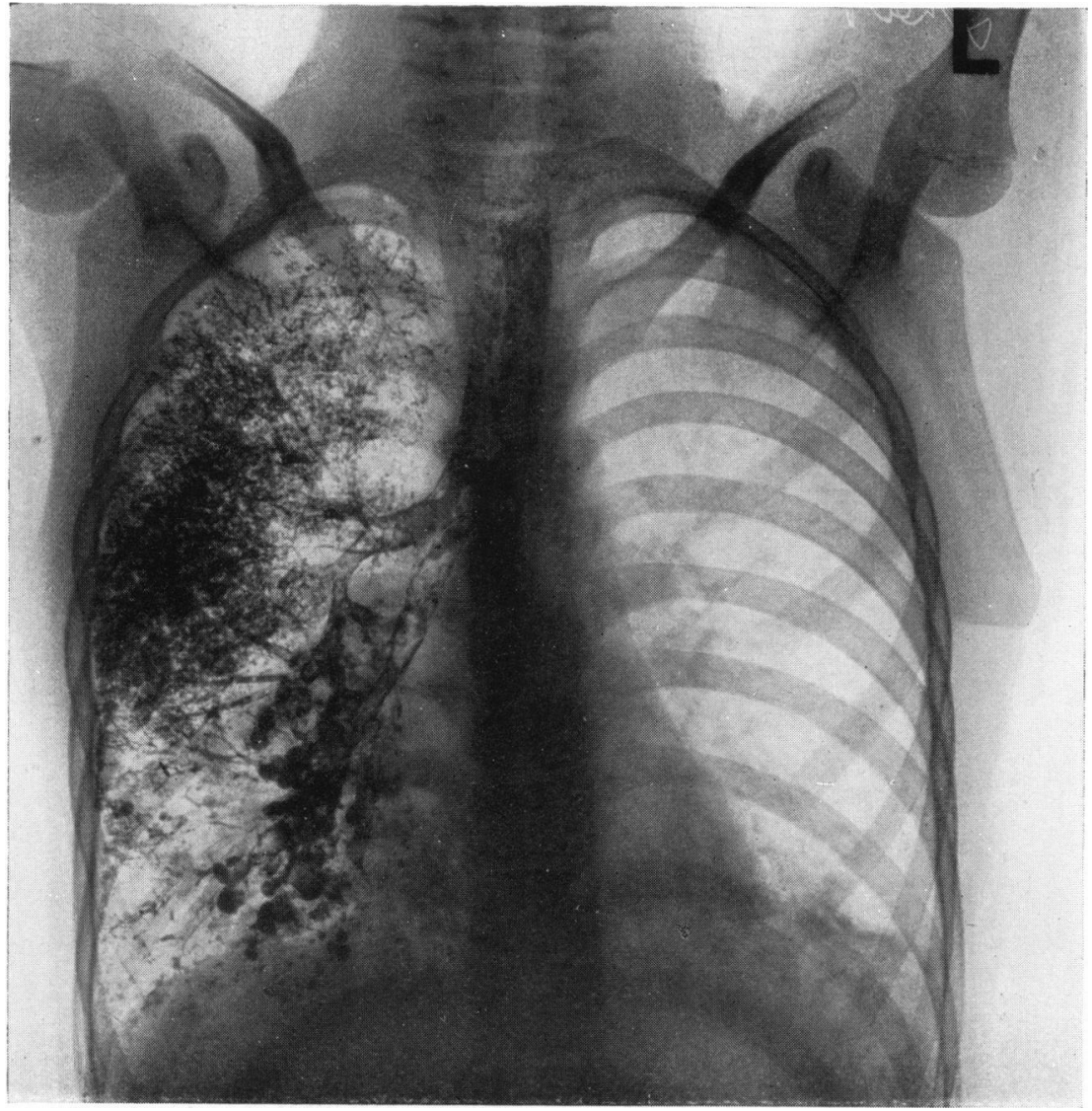

FIG. 11

presented no abnormal physical signs. The Mantoux test $(1: 1,000)$ was again strongly positive. X-ray examination of the chest (30.12.35) shows in the antero-posterior view (fig. 12) a triangular shadow, with a sharply-defined upper border and an ill-defined lower one (c.f. fig. 5, 8 and 10), the kase being directed towards the heart. In addition, there is an inner triangular shadow lying against the mediastinum. This is bounded externally by a sharply defined margin, directed downwards and outwards. In a lateral view (not here reproduced) these two triangular shadows were continuous with each other, producing a quadrangle, the lower border of which rested solely upon the diaphragm. From what has been said previously, it will be evident that this appearance was not produced by an affection of the middle lobe, but was due to an effusion lying in the great fissure, part of the effusion being situated against the mediastinum. This condition may be described as a mediastino-interlobar effusion. That this interpretation is correct is proved by two 
further series of x-rays. Those taken on 6.2.36 show, in the antero-posterior view (fig. 13), that the outer triangular opacity has now cleared, while, in the lateral view (fig. 14) the quadrangular shadow previously noted is very much smaller. In other words, the effusion in the large fissure has absorbed, but

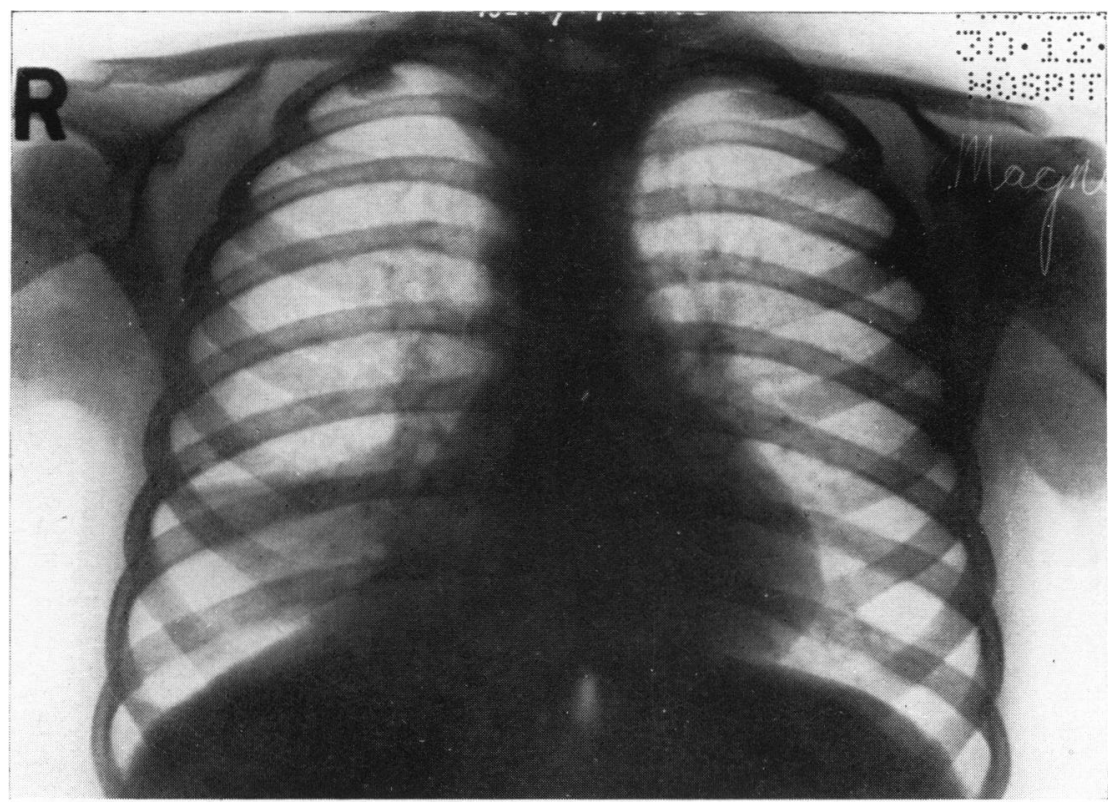

FIG. 12.

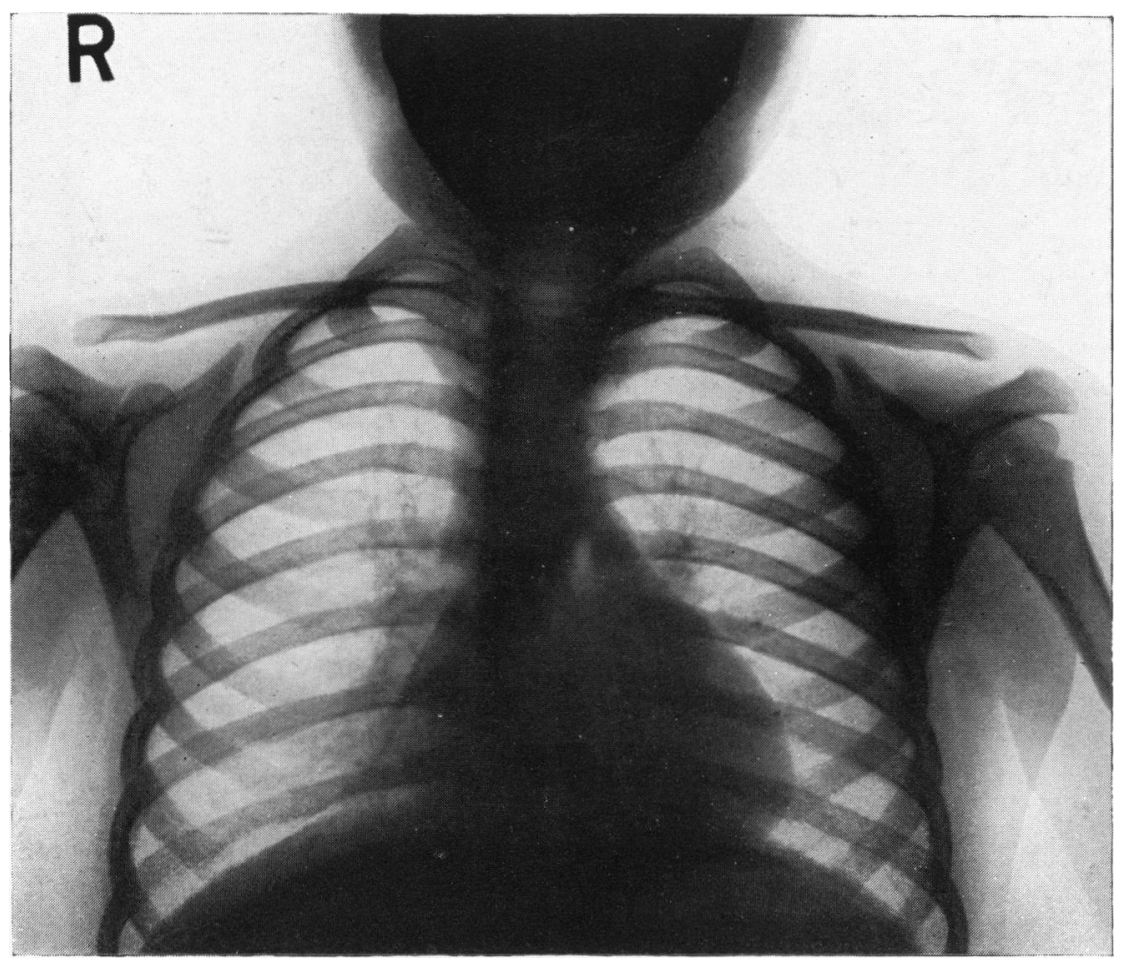

Fig. 13. 
the mediastinal portion of the effusion remains. X-ray examination after lipiodol on 18.2.36 showed conclusively that there was no collapse of either the middle or lower lobes. The latter diagnosis might have been suggested by the shape of the inner triangular shadow in the antero-posterior views (fig. 12 and 13).

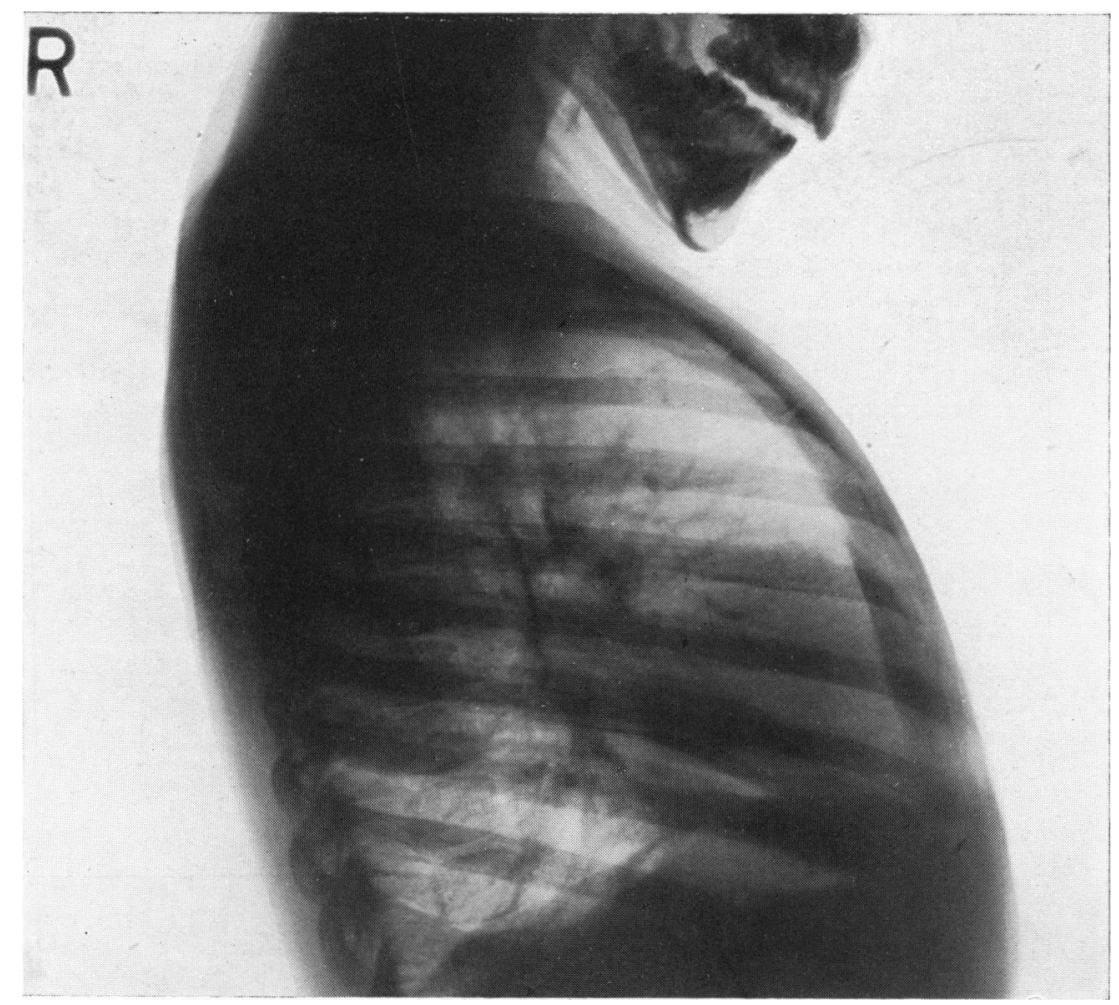

Fig. 14.

Summary.

1. The radiological and applied anatomy of the middle lobe and of the fissures which bound it is described.

2. The need for an accurate knowledge of this in relation to the differential diagnosis of middle lobe disease is emphasized.

3. Cases are described illustrating this and stressing the importance of good lateral x-ray pictures.

The authors' thanks are due to Dr. Graham Hodgson for his permission to reproduce the $\mathrm{x}$-ray photographs in this article.

REFERENCES.
1. St. Engel, \& Schall, L., Handb. d. Röntgen Diagnostik u. Therapie im Kindersalter, Leipzig, 1933, 253.

2. Sante, L. R., The Chest (Annals of Roentgenology, XI), New York, 1930, 456.

3. Pfaundler, M., \& Schlossman, A., Diseases of Children, Fourth Edition, transl. M. G. Peterman, Philadelph., 1935, IV, 543.

4. St. Engel, \& Schall, L., Handb. d. Röntgen Diagnostik u. Therapie im Kindersalter, Leipzig, 1933, 200.

5. Stoloff, E. G., The Chest in Children (Annals of Roentgenology, XII), New York, 1930, 80.

6. Reichle, H. S., \& York, C. H. Am. J. Dis. Child., Chicago, 1933, XLV., 771. 